RAMOS, F.A.S. et al. Análise descritiva de algumas características reprodutivas de um rebanho bovino leiteiro mestiço no Município de Coromandel-MG. PUBVET, Londrina, V. 8, N. 8, Ed. 257, Art. 1704, Abril, 2014.

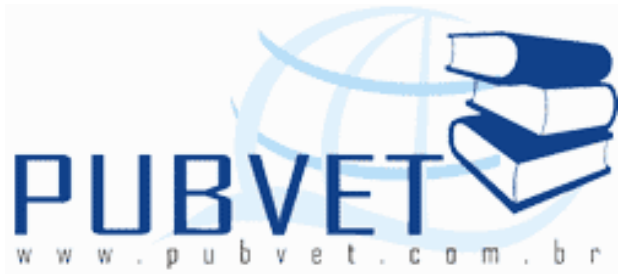

PUBVET, Publicações em Medicina Veterinária e Zootecnia.

\title{
Análise descritiva de algumas características reprodutivas de um rebanho bovino leiteiro mestiço no Município de Coromandel-MG
}

Fernando Alves Soares Ramos ${ }^{1}$; Lucas Padua Vilela ${ }^{1}$, Mara Regina Bueno de Mattos Nascimento ${ }^{2}$; Vitória Maria Simioni²

${ }^{1}$ Acadêmicos do Curso de Medicina Veterinária da Universidade Federal de Uberlândia.

${ }^{2}$ Docentes da Faculdade de Medicina Veterinária da Universidade Federal de Uberlândia.

\section{Resumo}

Determinaram-se algumas características reprodutivas de um rebanho bovino leiteiro mestiço da fazenda Figueredo, no município de Coromandel-MG, Brasil. Utilizou-se o programa SAS com a finalidade de realizar estudo descritivo do período de gestação (PG), intervalo de partos (IP) e período de serviço (PS) em vacas leiteiras mestiças. O PG médio foi de 273,57 dias $(9,11$ meses) com desvio padrão de 5,47 dias (0,18 meses), sendo o valor mais frequente de 271 dias (9,06 meses), com coeficiente de variação de 0,02\%, em 111 dados observados. O IP médio foi de 470,75 dias (15,69 meses) com desvio-padrão de 159,76 dias (5,32 meses), sendo o valor mais frequente de 385 dias (12,83 meses), com coeficiente de variação de 0,34\%, em 75 observações processadas. O PS médio foi de 197,54 dias (6,58 meses) com desvio padrão de 163,92 dias (5,44 meses), sendo o valor mais frequente de 60 dias (2 
RAMOS, F.A.S. et al. Análise descritiva de algumas características reprodutivas de um rebanho bovino leiteiro mestiço no Município de Coromandel-MG. PUBVET, Londrina, V. 8, N. 8, Ed. 257, Art. 1704, Abril, 2014.

meses), com coeficiente de variação de 0,83\%, em 102 registros processados. O intervalo de partos e o período de serviço mostraram-se acima do considerado adequado à uma exploração leiteira eficiente e econômica.

Palavras-chave: Vaca leiteira. Período de gestação. Intervalo de partos. Período de Serviço.

\title{
Descriptive analysis of some reproductive characteristics in crossbred dairy cows in the city of Coromandel-MG
}

\begin{abstract}
We determined some reproductive characteristics of a dairy cattle herd Figueredo mestizo farm in the town of Coromandel, Minas Gerais, Brazil. We used the SAS program in order to carry out the descriptive study of the gestation period (GP), calving interval (CI) and days open (DO) in crossbred dairy cows. The GP averaged 273.57 days (9.11 months) with a standard deviation of 5.47 days ( 0.18 months), being the most frequent value of 271 days (9.06 months), with a coefficient of variation of $0,02 \%$ in 111 observed data. The mean CI was 470.75 (15.69 months) with a standard deviation of 159.76 days ( 5.32 months) being the most frequent value of 385 days ( 12.83 months), with a coefficient of variation of $0,34 \%$ in 75 notes processed. DO The average was 197.54 days (6.58 months) with a standard deviation of 163.92 days ( 5.44 months), being the most frequent value of 60 days ( 2 months), with a coefficient of variation of $0.83 \%$ in 102 records processed. The calving interval and days open showed up the dairy farm is considered appropriate to efficiently and economically.
\end{abstract}

Keywords: Dairy cow. Period of gestation. Calving interval. Days open.

\section{INTRODUÇÃO}

Em 1975 a produção de leite no Brasil foi de 7.947.382 litros/ano, com uma produtividade de 646 litros/vaca/ano, em 2010 a produção foi de 
RAMOS, F.A.S. et al. Análise descritiva de algumas características reprodutivas de um rebanho bovino leiteiro mestiço no Município de Coromandel-MG. PUBVET, Londrina, V. 8, N. 8, Ed. 257, Art. 1704, Abril, 2014.

30.715.460 litros/ano, com uma produtividade de 1.340 litros/vaca/ano, no entanto, este aumento não foi totalmente relacionado à melhoria de desempenho de animais e, sim, ao número de vacas ordenhadas que cresceu de 12.293.66 para 23.508.605, nos respectivos anos (EMPRESA BRASILEIRA DE PESQUISA AGROPECUÁRIA-EMBRAPA, 2012).

De acordo com a EMBRAPA, do total da produção leiteira, o Estado de Minas Gerais foi responsável em 2010 pela produção de 8.388 .039 litros de leite, sendo que a região do Alto Paranaíba e Triângulo Mineiro produziu 2.093.463 litros, $24,95 \%$ do total do estado.

Os fatores socioeconômicos e políticos, além dos problemas de adaptação das raças leiteiras ao clima adverso da região tropical, estão certamente relacionados com produtividade e reprodução aquém do ideal do gado leiteiro no Brasil. Outro aspecto importante é a falta de utilização de metodologias eficientes de seleção entre e dentro das raças especializadas e, ou, adaptadas às peculiaridades do ambiente tropical (CAMARGO, 1994).

Outro fator importante que influencia a produtividade do rebanho leiteiro é a reprodução. O atraso no retorno à atividade ovariana pós-parto, maior período de serviço e de intervalo de partos, redução no período de lactação, menor produção de bezerros tanto por ano como durante a vida útil da matriz são exemplos de baixo desempenho reprodutivo. Os principais contribuintes com esta situação são fatores nutricionais, sanitários e problemas na identificação do estro. Por conseguinte, a manutenção de animais com baixa produção no rebanho contribui para aumentar o custo de produção de leite (SILVA; SOARES; SIMIONI, 2008).

Desse modo, torna-se, portanto, primordial conhecer o comportamento reprodutivo dos rebanhos por meio da adoção de metodologias estatísticas aplicadas a bancos de dados estabelecidos por escrituração zootécnica sistemática. Sendo assim, pode-se avaliar o quadro existente concretizando-se a identificação de novas metas, o conhecimento de fatores que comprometem o desempenho reprodutivo, além de indicar soluções às deficiências encontradas, corrigindo assim o problema e tornando a produção rentável. 
RAMOS, F.A.S. et al. Análise descritiva de algumas características reprodutivas de um rebanho bovino leiteiro mestiço no Município de Coromandel-MG. PUBVET, Londrina, V. 8, N. 8, Ed. 257, Art. 1704, Abril, 2014.

Dentro deste contexto, este estudo objetivou-se determinar algumas características reprodutivas, tais como: período de gestação, intervalo de partos e período de serviço de um rebanho bovino leiteiro mestiço, no município de Coromandel-MG, na região do Alto Paranaíba.

\section{MATERIAL E MÉTODOS}

Este estudo foi realizado com dados da fazenda Figueredo que está localizada na Rodovia MG-188, no município de Coromandel, Estado de Minas Gerais. O clima predominante é do tipo tropical, comum no Brasil Central, caracterizado por inverno seco (abril a setembro) e verão chuvoso (outubro a março). Sua área total corresponde a $75 \mathrm{ha}$, dos quais $15 \mathrm{ha}$ são de reserva obrigatória, 8ha destinados à silagem de milho e 1 ha de benfeitorias. Os 51 ha restantes são assim utilizados: 50ha formados por pastagem de Brachiaria decumbens (perfazendo cinco pastos) e um piquete de 1 ha formado por grama Cynodon dactylon var. Coast-Cross, onde são mantidos os bezerros.

A fazenda dispõe de instalações para manejo geral do rebanho com estábulos, bebedouros de alvenaria instalados nos currais e nos pastos, sala de ordenha com ordenhadeira mecânica. Dispõe ainda de um poço mini-artesiano para limpeza da sala de ordenha e abastecimento das residências e dos bebedouros.

Este rebanho constituiu-se de animais das raças Gir, Girolando e Holandesa e mestiços $1 / 2$ e $7 / 8$ Holandês-Gir.

Ao nascimento realiza-se o corte e a cura do umbigo e as bezerras mamam o colostro duas vezes ao dia, por dois dias, depois iam para o piquete, onde ficavam aproximadamente 120 dias. Neste recebem ração e sal mineralizado. A partir desta idade, são mantidas a pasto no período chuvoso e na seca recebem silagem de milho até atingirem $350 \mathrm{~kg}$ de peso vivo, sendo, então, submetidas à inseminação artificial.

No período chuvoso, no horário entre ordenhas, as vacas em lactação ficam em pastos de Brachiaria decumbens; na ordenha são divididas em lotes 
RAMOS, F.A.S. et al. Análise descritiva de algumas características reprodutivas de um rebanho bovino leiteiro mestiço no Município de Coromandel-MG. PUBVET, Londrina, V. 8, N. 8, Ed. 257, Art. 1704, Abril, 2014.

de acordo com a produção leiteira e recebem aproximadamente $1 \mathrm{~kg}$ de ração para cada $3 \mathrm{~kg}$ de leite produzido. No período seco, após a ordenha da manhã recebem silagem de milho e, ficavam neste curral até a ordenha da tarde. Após esta recebem silagem, porém no período chuvoso consumem apenas ração com sal sendo mantidas a pasto.

A deteç̧ão do estro era realizada de manhã e a tarde. As fêmeas que apresentam sinais clínicos são inseminadas 12 horas após. Animais que não emprenham após a $3^{a}$ inseminação são cobertos por touros de repasse.

As características avaliadas neste estudo foram: período de gestação, intervalo de partos e período de serviço. O período de gestação, em dias, foi calculado pelo tempo decorrido entre as datas da última inseminação fértil e do próximo parto. O período de serviço foi obtido pelo intervalo de dias entre o parto e a próxima concepção. Intervalo de partos, em dias, considerou-se o intervalo entre duas parições consecutivas de um mesmo animal.

Foi utilizado o programa estatístico SAS (1990), para a formação de arquivos, consistência e análise descritiva dos dados para as características avaliadas.

\section{RESULTADOS E DISCUSSÃO}

O período de gestação médio encontrado foi de 273,57 dias $(9,11$ meses) com desvio padrão de 5,47 dias $(0,182$ meses), sendo o valor mais frequente de 271 dias (9,06 meses), com coeficiente de variação de 0,02\%, em 111 registros processados (Tabela 1 ).

A variação fenotípica do período de gestação apresenta uma pequena amplitude, entretanto, existem diferenças entre indivíduos de uma mesma raça e entre raças (SILVA et al., 2008). Estes autores citam ainda que o período de gestação é geneticamente determinado, embora possa ser modificado por fatores maternos (idade da matriz) e fetais (fetos múltiplos, sexo e tamanho do feto). O período de duração de prenhez é fundamental para 
RAMOS, F.A.S. et al. Análise descritiva de algumas características reprodutivas de um rebanho bovino leiteiro mestiço no Município de Coromandel-MG. PUBVET, Londrina, V. 8, N. 8, Ed. 257, Art. 1704, Abril, 2014.

se diferenciar o parto normal, do aborto ou do parto retardado (SCARPATI, 1997).

Tabela 1: Período de gestação, intervalo de partos e período de serviço, em dias, de um rebanho bovino leiteiro mestiço no município de Coromandel-MG.

\begin{tabular}{lccc}
\hline & $\begin{array}{c}\text { Período de } \\
\text { Gestação }\end{array}$ & $\begin{array}{c}\text { Intervalo de } \\
\text { Partos }\end{array}$ & Período de Serviço \\
\hline Número observações & 111 & 75 & 102 \\
Média & 273,57 & 470,75 & 197,54 \\
Desvio padrão & 5,47 & 159,76 & 163,92 \\
Amplitude & 39,00 & 650,00 & 712,00 \\
Moda & 272,00 & 385,00 & 60,00 \\
Coeficiente de variação & 0,02 & 0,34 & 0,83 \\
\hline
\end{tabular}

O valor médio do período de gestação encontrado neste estudo foi próximo aos constatados por Silva e Simioni (2005) e, por Bueno e Simioni (2006b), que constataram, respectivamente, 274,40 e 273,79 dias. No entanto, foi inferior às médias relatadas por Simioni (1997), 279,80 dias, Cunha et al. (2006), 278,69 dias e, por Bonato e Simioni (2010), 276,45 dias.

A média e o desvio-padrão do intervalo de partos foram de 470,75 \pm 159,76 dias (15,69 $\pm 5,32$ meses) sendo o valor mais frequente de 385 dias (12,83 meses), com coeficiente de variação de 0,34\%, em 75 observações processadas. Neste estudo a média do intervalo de partos foi bem superior ao ideal que é de 12-14 meses. Conforme Pereira (2008), as estimativas de herdabilidade para intervalo de partos são geralmente baixas ou nulas, o que indica pouca ou nenhuma ação genética aditiva. Dessa forma, vários fatores ambientais podem estar contribuindo para obter intervalo de parto longo, dentre eles, nutrição, detecção de estro, reduzido descarte de vacas com baixa eficiência reprodutiva e sanidade. Portanto, resultados de curto prazo com a 
RAMOS, F.A.S. et al. Análise descritiva de algumas características reprodutivas de um rebanho bovino leiteiro mestiço no Município de Coromandel-MG. PUBVET, Londrina, V. 8, N. 8, Ed. 257, Art. 1704, Abril, 2014.

finalidade de reduzir esta característica podem ser obtidos por meio de melhorias substanciais na alimentação e no manejo geral das fêmeas.

A média de 470,75 dias (15,69 meses) foi superior às obtidas por Guimarães et al. (2002), Sousa (2002), Manzan et al. (2003), Ferreira et al. (2004), Machado e Simioni (2004), Simioni e Silva (2005b), Rufino e Simioni (2006a) e, por Simioni e Bueno (2006), que constataram, respectivamente, 414,$70 ; 438,90 ; 404,10 ; 381,21 ; 364,65 ; 430,00 ; 363,38 ; 433,00 ;$ e 364,27 dias. No entanto, foi inferior às médias relatadas por Costa et al. (2004), que relataram, respectivamente, 501,46; 579,51 dias.

O período de serviço médio foi de 197,54 dias (6,58 meses) com desvio padrão de 163,92 dias (5,44 meses), sendo o valor mais frequente de 60 dias, com coeficiente de variação de 0,83\%, em 102 observações processadas. Esta média foi superior à considerada ideal para novilhas Holandês $x$ Zebu no Brasil, que é de até 100 dias, conforme Ferreira et al. (2001). A média obtida neste estudo foi superior às encontradas por Machado e Simioni (2004), Costa e Simioni (2004), Bueno e Simioni (2006a) e por Rufino e Simioni (2006b) que encontraram valores de 152,16; 116,77; 90,12 e 155,19 dias.

Neste estudo o valor médio de período de serviço observado foi demasiadamente elevado o que compromete a obtenção de um período de intervalo de parto ideal (12 meses). Vários fatores podem estar influenciando este elevado índice. Dentre eles, nutricional, deficiência na pressão de seleção para fertilidade, doenças infecciosas, falhas tanto dos inseminadores quanto da detecção do estro. Portanto, recomenda-se adequado manejo nutricional no pré e pós-parto, descarte de matrizes de baixa eficiência reprodutiva, manejo profilático-sanitário eficiente, constante treinamento dos inseminadores e maior eficácia na deteç̧ão do estro. Do ponto de vista do melhoramento genético, períodos de serviços longos induzem a menores intensidades seletivas a serem aplicadas e, consequentemente, refletem de forma desfavorável sobre os ganhos genéticos a serem alcançados (BONATO; SIMIONI, 2010). 
RAMOS, F.A.S. et al. Análise descritiva de algumas características reprodutivas de um rebanho bovino leiteiro mestiço no Município de Coromandel-MG. PUBVET, Londrina, V. 8, N. 8, Ed. 257, Art. 1704, Abril, 2014.

\section{CONCLUSÃO}

O período de gestação esteve dentro dos padrões citados na literatura, uma vez que trata de uma característica fenotipicamente pouco variável.

Os valores de intervalo de partos e do período de serviço mostraram-se acima do considerado adequado à exploração leiteira eficiente e econômica. Assim, recomenda-se identificar os fatores que, de fato, estão contribuindo para alongar estas características reprodutivas que podem ser melhoradas com estratégias de alimentação, com o aperfeiçoamento na deteç̧ão do estro, reciclagem do inseminador, manejo sanitário adequado e maior pressão de seleção de fêmeas com base na fertilidade.

\section{REFERÊNCIAS}

BONATO, G. L.; SIMIONI, V. M. Estatísticas descritivas de características reprodutivas de um rebanho Holandês x Gir no município de Monte Alegre-MG. Horizonte Científico, Uberlândia, v. 4, n. 2, 2010.

BUENO, C. P.; SIMIONI, V. M. Análise descritiva do período de serviço em um rebanho leiteiro do município de São Gotardo. In: SEMANA ACADÊMICA DA UNIVERSIDADE FEDERAL DE UBERLÂNDIA, 3., 2006, Uberlândia. Anais... Uberlândia: UFU, 2006a. 1 CD - ROM.

BUENO, C.P.; SIMIONI, V.M. Avaliação do período de gestação e da proporção de sexos em um rebanho leiteiro no município de São Gotardo. In: SEMANA ACADÊMICA DA UNIVERSIDADE FEDERAL DE UBERLÂNDIA, 3., 2006. Uberlândia. Anais... Uberlândia: UFU, 2006b. 1 CD Rom.

CAMARGO, A. J. R. Estudo de algumas características produtivas e reprodutivas de um rebanho mestiço Holandês - Zebu no Estado do Rio de Janeiro. 1994. 81 f. Dissertação (Mestrado em Zootecnia) - Universidade Federal de Viçosa, Viçosa, 1994.

COSTA, R. P; CARVALHO JÚNIOR, H.J.; SIMIONI, V.M. Comportamento reprodutivo de mestiças Holandês $x$ Zebu no município de Corumbaíba - GO. In: SEMANA CIENTÍFICA DE MEDICINA VETERINÁRIA, 17., 2004, Uberlândia. Anais... Uberlândia: UFU: FAMEV, 2004.1 CD - Rom.

CUNHA, M.C.G.; RUFINO, M.A.; SIMIONI, V.M. Estudo descritivo do período de gestação em um rebanho mestiço leiteiro do município de Tupaciguara. In: SEMANA ACADÊMICA DA UNIVERSIDADE FEDERAL DE UBERLÂNDIA, 3., 2006. Uberlândia. Anais... Uberlândia: UFU, 2006. 1 CD - Rom.

EMPRESA BRASILEIRA DE PESQUISA AGROPECUÁRIA-EMBRAPA, 2012. Disponível em: <http://www.cnpgl.embrapa.br/nova/informacoes/estatisticas/producao/tabela0232.php> Acesso em: 17 set. 2013. 
EMPRESA BRASILEIRA DE PESQUISA AGROPECUÁRIA-EMBRAPA, 2012. Disponível em: < http://www.cnpgl.embrapa.br/nova/informacoes/estatisticas/producao/tabela0240.php > Acesso em: 17 set. 2013.

EMPRESA BRASILEIRA DE PESQUISA AGROPECUÁRIA-EMBRAPA, 2012. Disponível em: <http://www.cnpgl.embrapa.br/nova/informacoes/estatisticas/producao/tabela0242.php> Acesso em: 17 set. 2013.

FERREIRA, A. M.; SÁ, W. F.; CAMARGO, L. S. A.; VIANA, J. H. M. Manejo Reprodutivo de Rebanhos Leiteiros. In: Embrapa Gado de Leite; FEPALE. (Org.). Capacitação em

Tecnologias para Produção de Leite nos Trópicos. 1. ed. Juiz de Fora: Embrapa Gado de Leite, 2001, v. 1, p. 85-97.

FERREIRA, C.M.; SIMIONI, V.M.; FERREIRA, C.M. Comportamento reprodutivo em matrizes mestiças e PC Holandês $X$ Zebu de um rebanho do município de Divinópolis - MG. In: SEMANA ACADÊMICA DA UNIVERSIDADE FEDERAL DE UBERLÂNDIA, 1., 2004. Uberlândia. Anais... Uberlândia: UFU, 2004. 1 CD - Rom.

GUIMARÃES, J.D.; ALVES, N.G., COSTA, E.P.; SILVA, M.R.; COSTA, F.M.J; ZAMPERLINI. Eficiências reprodutiva e produtiva em vacas das raças Gir, Holandês e cruzadas Holandês $x$ Zebu. Revista Brasileira de Zootecnia, Viçosa, v. 31, n. 2, 2002.

MACHADO, C.A.; SIMIONI, V.M. Comportamento de algumas características reprodutivas em matrizes mestiças Holandês $x$ Gir de um rebanho do município de Araguari - MG. In: SEMANA ACADÊMICA DA UNIVERSIDADE FEDERAL DE UBERLÂNDIA, 1., 2004, Uberlândia. Anais... Uberlândia: UFU, 2004. v. 1. p. 71, 1 CD - Rom.

MANZAN, R.M.; SIMIONI, V.M.; MANZAN, V.L. Análise descritiva de algumas características reprodutivas de um rebanho mestiço leiteiro Europeu $x$ Zebu. Veterinária Notícias, Uberlândia, v. 9, p. 32, Jun. 2003. Supl. 1.

PEREIRA, J. C. C. Melhoramento genético das raças zebus. In: PEREIRA, J. C. C.

Melhoramento genético aplicado à produção animal. Belo Horizonte: FEPMVZ, 2008. Capítulo 14, p. 329-387.

RUFINO, M.A.; SIMIONI, V.M. Avaliação descritiva do intervalo de partos em um rebanho mestiço leiteiro do município de Tupaciguara. In: SEMANA ACADÊMICA DA UNIVERSIDADE FEDERAL DE UBERLÂNDIA, 3., 2006. Uberlândia. Anais... Uberlândia: UFU, 2006a. 1 CD Rom.

RUFINO, M.A.; SIMIONI, V.M. Comportamento do período de serviço em um rebanho mestiço leiteiro do município de Tupaciguara. In: SEMANA ACADÊMICA DA UNIVERSIDADE FEDERAL DE UBERLÂNDIA, 3., 2006. Uberlândia. Anais... Uberlândia: UFU, 2006b. 1 CD - Rom. SCARPATI, M. T. V. Modelos animais alternativos para estimação de componentes de co-variância e de parâmetros genéticos e fenotípicos do período de gestação na raça nelore. 1997. 70 f. Dissertação (Mestrado em Genética). Universidade de São Paulo: Faculdade de Medicina de Ribeirão Preto, Ribeirão Preto, 1997.

SILVA, D. M. da; SIMIONI, V. M. Avaliação descritiva do período de gestação de um rebanho bovino leiteiro. In: SEMANA ACADÊMICA DA UNIVERSIDADE FEDERAL DE UBERLÂNDIA, 2., 2005, Uberlândia. Anais... Uberlândia: UFU, 2005. 1 CD -Rom. 
SILVA, D.M. da; SIMIONI, V.M. Estatística descritiva da idade à primeira fecundação de um rebanho bovino leiteiro. In: SEMANA ACADÊMICA DA UNIVERSIDADE FEDERAL DE UBERLÂNDIA, 2., 2005, Uberlândia. Anais... Uberlândia: UFU, 2005b. 1 CD - Rom.

SILVA, E. V.; SOARES, P.; SIMIONI, V. M. Estudo descritivo de características reprodutivas e da produção de leite de um rebanho bovino mestiço no município de Uberlândia, Horizonte Científico, Uberlândia, v.2, n.1, 2008. Disponível em:

<http://www.seer.ufu.br/index.php/horizontecientifico/article/view/4020/2996>. Acesso em: 16 jul. 2013.

SIMIONI, V. M. Análise descritiva da duração do período de gestação do rebanho leiteiro da Fazenda Córrego do Glória - UFU. In: SEMANA DE CIÊNCIAS AGRÁRIAS, 4., 1997. Uberlândia. Anais... Uberlândia: UFU, 1997. 1 CD - Rom.

SIMIONI, V.M.; BUENO, C.P. Estudo do comportamento do intervalo entre partos em um rebanho leiteiro no município de São Gotardo. In: SEMANA ACADÊMICA DA UNIVERSIDADE FEDERAL DE UBERLÂNDIA, 3., 2006. Uberlândia. Anais... Uberlândia: UFU, 2006. 1 CD Rom.

SOUSA, M. A. A obtenção de bezerro de boa qualidade e a produção de leite. 2002. Disponível em: < http://www.ceplac.gov.br/radar/semfaz/producaodeleite.htm> Acesso em: 20 ago 2013. 